Fig. 2. At surface, where the veins have been affected by atmospheric agencies, there is a high proportion of metallic silver. Much of the ore shipped in Igo4 was largely composed of native silver. The discovery at Cobalt is an indication of Canada's bright prospects of becoming a more important mineralproducing country. In North America the territory controlled by Great Britain exceeds that of the United States. But of this immense area of $3,600,000$ square

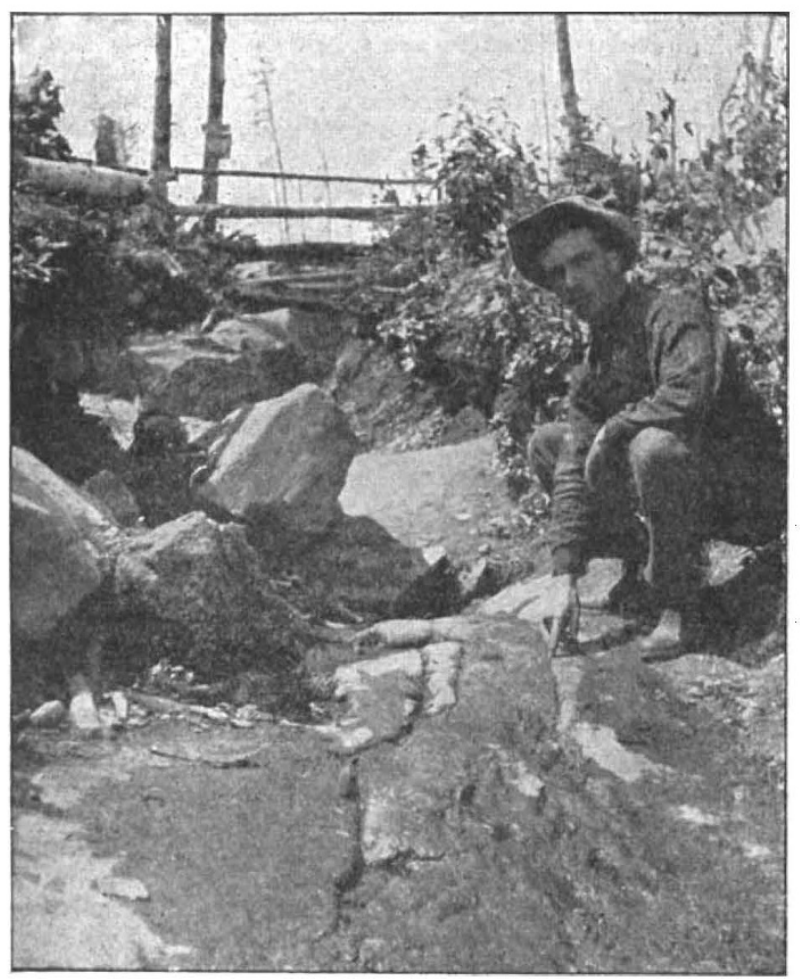

FIG. 2.-Metallic Outcrop of Silver Ore, Cobalt. From "Mines and Minerals of the British Empire."

miles only a very narrow fringe has even been explored, and yet the rocks of which a very large proportion of the unexplored area is in all probability composed are those which in the United States carry the most valuable mineral deposits. Here, and in other parts of the Empire, the world awaits the establishment of new mining regions to compensate for the steady impoverishment of the old.

\section{THE SECONDARY OSCILLATIONS OF OCEANIC TIDES.}

TIDAL observers have long known that at certain stations, mostly situated on bays or indentations of the coast, the simple curve of the tide-gauge is complicated by oscillations of level, often of considerable range and regularity of period. At first sight nothing could be further removed from the study of earthquakes than these irregularities of the tidal oscillation, but a connection has been discovered by the Japanese Earthquake Investigation Committee,

1 "An Investigation on the Secondary Undulations of Oceanic Tides, carried out by the Order of the Earthquake Investigation Committee during 1903-6." By Drs. K. Honda, T. Terada, Y. Yoshida and D. Isitani. Preface by Prof. H. Nagaoka. Pp. viii $+x_{13} ; 05$ plates, 2 frontispieces. Published as No. 26 of Publications of the Eartbquake Investigation Committee in Foreign Languages, and as vol. xxiv. of the Journal of the College. of Science, Imperial University of Tokyo. (Tokyo, Igo8.) whose diverse activity leads it to the study, not only of everything directly or indirectly connected with earthquakes, but also of everything which resembles their effect. The discovery, by Prof. Omori, that the periods of the earthquake-produced sea-waves were not uniform at neighbouring stations, but in each case agreed with those of the secondary oscillations of the tidal curve, naturally led to an investigation of this phenomenon, which has been noticed and made the subject of speculation by various observers. The investigation was carried out under the direction of Prof. H. Nagaoka, and has been published in a bulky and profusely illustrated quarto volume.

After a description of the improved and portable form of tide-gauge which was invented for the investigation, the ordinary limnograph being unsuitable and the ordinary tide-gauge too cumbrous, we have a detailed account, illustrated by reprociuctions of the tide curves and charts, of the records from fifty-one stations on the Japanese coasts. A general summary of the results is given, from which it appears that on the open Pacific coast, or in a bay of considerable area communicating with the sea by a narrow outlet, the tide curve is of a simple character, the secondary oscillations being small and irregular; but in more open bays, the breadth of which is not too large in comparison with their length, secondary oscillations are conspicuous, and often show great regularity of period. Simultaneous observations at different places along the shore-line showed that the phase of oscillation was usually the same throughout the bay, and that the oscillations which were conspicuous within the bay could be detected, with the same phase, but much reduced amplitude, at its mouth. From this it appeared that the whole mass of water in the bay was in simultaneous oscillation in a stationary wave, analogous to the sound-wave in an open organ pipe, and that the bay selected from the multitudinous ocean waves of various period the particular one to which it was able to respond, and, like a resonator with sound-waves, magnified and made it conspicuous.

This conclusion was verified by experimental investigation. Models, to scale, of the bays were made and sunk to the appropriate level in a large tank of water; in this tank was immersed a leaden ball which, being attached to a simple or a horizontal pendulum, could be set in oscillation with any desired period, and by its movement communicate to the water in the tank a periodic oscillation, unaccompanied by any appreciable surface-wave; reflection from the walls of the tank being checked by a thick layer of damping material-wood-shavings, to wit. By exciting waves with this arrangement the water in the model of the bay was put into standing oscillation, the amplitude of which was generally small; as the period of the pendulum approached the proper period of the bay, the amplitude of oscillation gradually increased, and, when the period exactly coincided with that of the model, the amplitude reached its maximum, continuing, with a regular period, after the pendulum was stopped. The phase of the water particles was the same for all parts of the bay when the oscillation was a fundamental one, but a binodal or trinodal oscillation was easily produced in an elongated bay.

An ingenious development of the experiment consisted in sprinkling aluminium powder on the surface of the water and photographing the model with a camera suspended vertically above it; by giving an appropriate length of exposure, the movement of the particles-reproduced the course of the stream-lines on the resulting photograph. In Fig. I we reproduce one of these photographs, showing the motion where the induced wave is the fundamental oscillation, in which the mouth of the bay is a node for NO. 2020, VOL. 78] 
vertical and a loop for horizontal motion, while the head is a loop for vertical and a node for horizontal

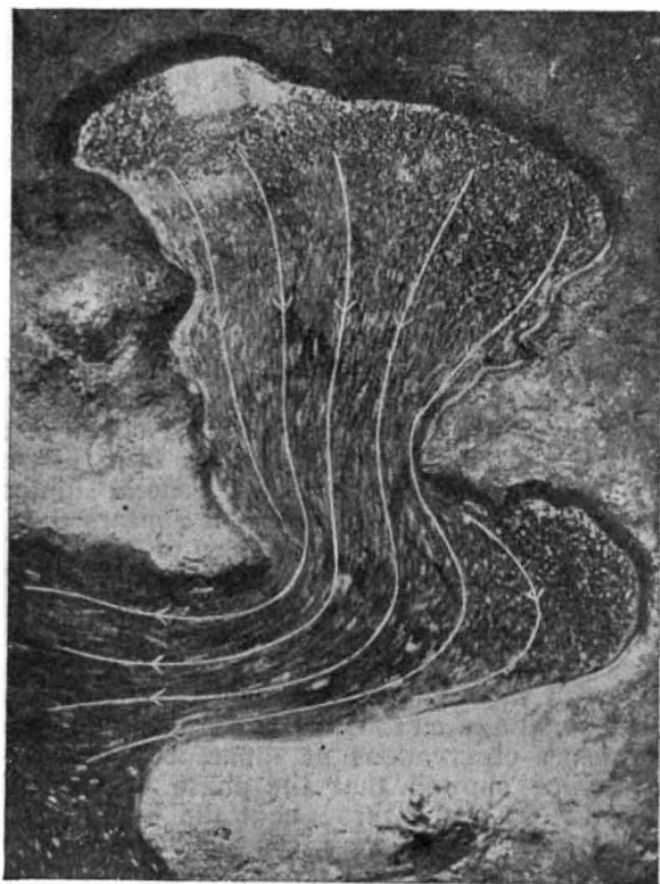

F1G. x.-Model of Aomori Bay, showing stream lines of fundament 1 osci!lation: period $4^{\circ} 453$ in model, $r \in$ presenting $3 \circ 3 \mathrm{~m}$. in the bay itself.

motion. The period of this oscillation in the model was $4^{\circ} 45$ seconds; the factor, corresponding to the scale adopted, being 409o, this represents a period of

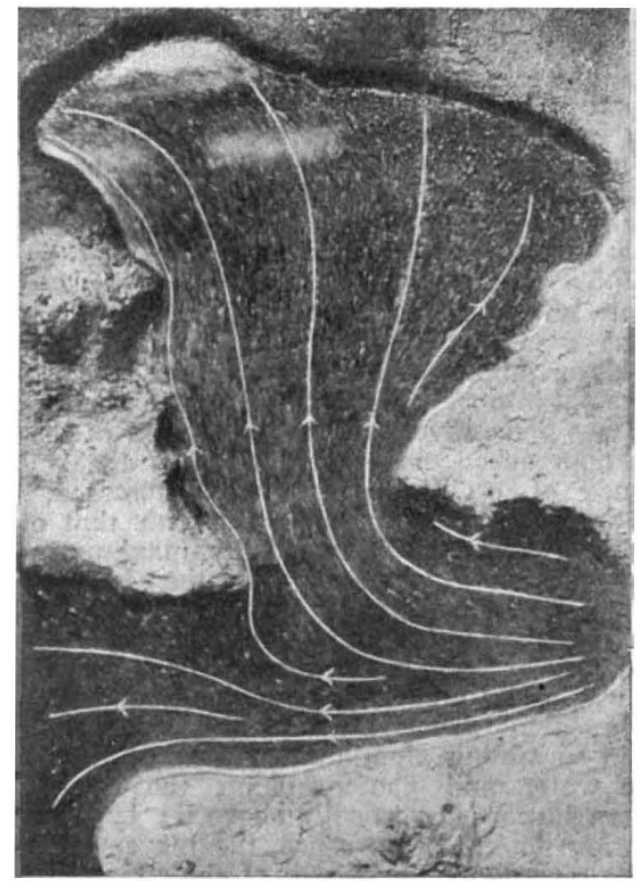

FIG. 2.-Model of Aomori Bay, showing stream lines of lateral oscillation : period $\mathrm{r}^{\circ} 6_{3}$ in model, representing $108 \mathrm{~m}$, in the bay itself.

$303 \mathrm{~m}$. in the actual bay, in which a periodic oscillation of $300 \mathrm{~m}$. was observed. Besides this NO. 2020, VOL. 78] fundamental wave, the water within the bay could be set into lateral oscillation, as shown in Fig. 2, with a period of $I^{*} 60 \mathrm{~s}$. in the model, representing $108 \mathrm{~m}$. in the actual bay, where a well-marked regular undulation of $\mathrm{IO} 3 \mathrm{~m}$. was observed.

The account of the experiments is followed by a mathematical treatment of the subject, and a calcula. tion of the periods of the stationary waves for each of the bays investigated, a calculation which gave results in general, and sometimes in close, accordance with the observed periods. Finally, there is a suggestion that the great increase in the range of tides near the head of large bays may be partly due to this cause. The Bay of Fundy is celebrated for the great range of the tide near its head, where the difference between high and low water is from 50 to to feet, while near the mouth the range is not more than 7 to ro feet; the difference is partly attributable to the banking of the tidal wave as it travels up a narrowing channel, but, the fundamental period of oscillation of the bay being about twelve hours, it is by no means improbable that this has a material effect in increasing the range of the semi-diurnal tide, with which it approximately agrees in period.

We have indicated sufficiently the scope of this important memoir, the unseismological interest of which has been recognised by its simultaneous appearance as one of the publications of the Earthquake Investigation Committee and as a volume of the Journal of the College of Science of Tokyo.

\section{VESTIGES OF SCALES IN THE FOX.}

$\mathrm{N}$ the case of such a familiar animal as the fox 1 it might well have been supposed that everything worth knowing in the matter of its bodily structure had already been recorded. That this is not so is demonstrated in an article by Mr. K. Toldt, of Vienna, published in the April number of the Zoologischer Anzeiger, where it is shown, on what appears to be practically conclusive evidence, that the fox is descended from ancestors the bodies of which appear to have been clothed with horny scales like those of the pangolins, or scaly ant-eaters. Although these scaly ant-eaters are the only living mammals the bodies of which are completely covered with overlapping scales, armadillos furnish us with an example of another type of armour in the same class; while there are several groups of mammals in which some portion of the body is scaly. In the rat, for example, the whole tail is scaled, and more or less distinctly scaled areas are met with in several porcupines and certain other rodents, as well as on the tail of the great South American anteater. In all cases where hairs grow from the body between the scales (as they almost invariably do), such hairs, in place of being scattered about in an irregular manner, have a certain definite arrangement. They grow, for instance, in isolated bundles, arranged in some cases in groups of three or four, and placed at regular intervals from one another.

From the fact that the hairs are arranged in this peculiar and definite fashion in a number of species which show no traces of scales, it has been suggested that such mammals trace their descent from scaleclad ancestors.

Careful examination of the skins of young foxes has enabled Mr. Toldt to announce, not only that the hairs are arranged in this peculiar fashion, namely, in groups of three bundles, each containing some:fourteen or fifteen hairs, but likewise that the skin itself actually exhibits a structure such as would be presented by that of a pangolin after the scales had been pulled out. Viewed'through a microscope, the skin presents, 